
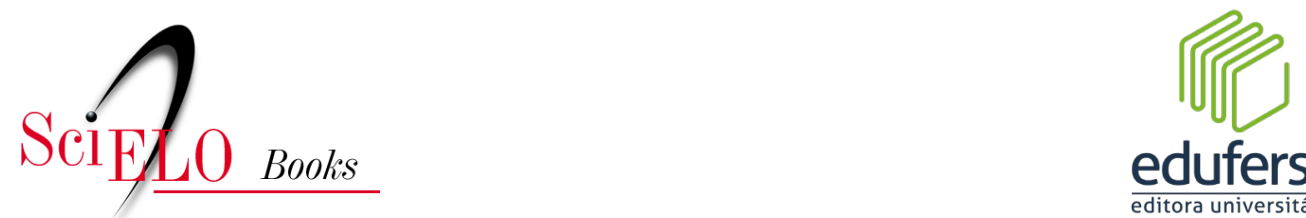

edufersa

editora universitária

\title{
4 - O conhecimento sobre a biodiversidade de insetos como patrimônio rural
}

\author{
Rodolfo Rafael Pascoal da Penha \\ Giordano Gubert Viola \\ Daniela Faria Florencio
}

\section{SciELO Books / SciELO Livros / SciELO Libros}

PENHA, R. R. P., VIOLA, G. G., and FLORENCIO, D. F. O conhecimento sobre a biodiversidade de insetos como patrimônio rural. In: OLIVEIRA, G. M. C., and VIEIRA, K. M. A., eds. Patrimônio, povos do campo e memórias: diálogos com a cultura, a arte e a educação [online]. Mossoró: EdUFERSA, 2020, pp. 67-80. ISBN: 978-65-87108-09-4. https://doi.org/10.7476/9786587108605.0005.

\section{(c) (1)}

All the contents of this work, except where otherwise noted, is licensed under a Creative Commons Attribution 4.0 International license.

Todo o conteúdo deste trabalho, exceto quando houver ressalva, é publicado sob a licença Creative Commons Atribição 4.0. 


\title{
O CONHECIMENTO SOBRE A \\ BIODIVERSIDADE DE INSETOS \\ COMO PATRIMÔNIO RURAL ${ }^{21}$
}

\author{
Rodolfo Rafael Pascoal da Penha \\ Giordano Gubert Viola \\ Daniela Faria Florencio
}

\section{Introdução}

Esse texto é discorrido a partir de uma pesquisa de Trabalho de Conclusão de Curso desenvolvida no curso de Licenciatura Interdisciplinar em Educação do Campo (Penha, 2018). O nosso trabalho discute sobre o conhecimento dos/as agricultores/as acerca da biodiversidade de insetos e sua relação com a agricultura como patrimônio rural.

Existem pelo menos duas práticas de agricultura bem distintas, a agricultura agroecológica e a agricultura convencional ou industrial. As atividades e métodos utilizados são diferenciados de cada agricultor/a e cada modelo tem seus mecanismos de relação com o meio natural e social.

O modelo convencional trabalha com base na tecnologia industrial, utilizando máquinas e agroquímicos para realizar os seus cultivos de forma que esboçam uma necessidade demasiada de produzir grandes quantidades voltadas para a exportação para outros países, como exemplo o polo de fruticultura de Petrolina/PE e Juazeiro/BA que tem sua produção voltada para a exportação para outros países (SANTOS; OLIVEIRA, 2019). Esse modelo vem contribuindo para o êxodo rural, a introdução de espécies exóticas e uso indiscriminado de fertilizantes e agrotóxico. Segundo Mariani

21 Parte desse trabalho foi apresentado no XI Congresso Brasileiro de Agroecologia (XI CBA). 
e Henkes (2015) o Brasil é maior comprador de agrotóxicos do mundo e as consequências do uso de agroquímicos têm causado impactos negativos na biodiversidade biológica e cultural pela contaminação do solo, da água e do ar (STEFFEN; STEFFEN; ANTONIOLLI, 2011).

O modelo agroecológico, por sua vez, se comporta de forma sustentável, busca respeitar o ambiente e realiza uma produção saudável e autossustentável (GAIOVICZ; SAQUET, 2009). A agroecologia tem como preceito a valorização do conhecimento popular, o conhecimento local dos/as agricultores/as (GLIESSMAN, 2008) e busca se relacionar com a biodiversidade dos ecossistemas a fim de realizar uma boa interação com a biodiversidade, gerando uma produção entre homem e a natureza (TAVARES, 2009).

A biodiversidade de insetos é fundamental para os ecossistemas assim como para os agroecossistemas, pois os insetos auxiliam na (i) polinização; (ii) controle biológico: predadores e parasitóides; (iv) ciclagem de nutrientes; (v) aeração e revolvimento do solo; (vi) alimentação humana e animal; (vii) medicina popular (MACENA, 2011; CUNHA; NÓBREGA; ANTONIALLI JUNIOR, 2015; PARRA et al., 2002; EGGLETON et al., 1996; Sileshi et al., 2009) Entretanto, quando em desequilíbrio a perda da biodiversidade pode acarretar a perda de funções e serviços essenciais (DIRZO et al., 2014) e algumas populações podem causar prejuízos recebendo o nome de pragas (GULLAN, CRANSTON, 2017). Neste sentido, a preservação da biodiversidade permite um equilíbrio natural de forma que as teias alimentares por si só irão propiciar o equilíbrio das populações, visto que quanto maior a biodiversidade maior tende a ser a resistência às espécies invasoras e à estabilidade dos ecossistemas (TILMAN, 1999). O quanto mais estável os ecossistemas se encontrarem, os problemas ambientais serão de proporções menores.

Com base nessas questões é pertinente pensar: quais as concepções e técnicas de manejo da biodiversidade de insetos, em especial dos cupins, são praticadas por agricultores/as agroecológicos e por trabalhadores/as rurais do Oeste Potiguar? Assim, esse trabalho teve como objetivo compreender o conhecimento dos/as agricultores/as agroecológicos/as e dos/as trabalhadores/as rurais do agronegócio do semiárido potiguar, sobre a biodiversidade insetos, em especial dos cupins. 
Foram realizadas entrevistas semiestruturadas, constituídas de perguntas abertas, com agricultores/as agroecológicos e com trabalhadores/as rurais dos municípios de Mossoró e Apodi, mesorregião Oeste do Rio Grande do Norte. A escolha dessa metodologia possibilita uma maior exploração das questões de interesse da pesquisa (Marconi, Lakatos, 2010), posto que a entrevista semiestruturada possibilita a obtenção de informações sobre os diversos aspectos da vida social e tem se constituído em uma técnica bastante eficiente para a obtenção de informações em profundidade acerca do comportamento humano, possibilitando o desenvolvimento de análises mais amplas acerca de determinados fenômenos (GIL, 2019).

Nossos/as colaboradores/as foram selecionados de forma aleatória, posterior a um levantamento prévio de cada grupo, no qual se prontificaram em participar de nossa pesquisa. Aqui será feito um recorte sobre os achados dessa pesquisa, ressaltando o conhecimento dos/as nossos/as colaboradores/as, estes que contribuíram para o nosso escrito ${ }^{22}$. As identidades estarão preservadas, e para tanto utilizou-se de A1, A2, A3, A4, A5 para identificar os/as agricultores/as agroecológicos e T1, T2, T3, T4, T5 para os trabalhadores rurais.

\section{Agricultura e agricultores/as: relações com a biodiversidade de insetos}

O patrimônio rural natural está associado com o conhecimento construído a partir das experiências e da herança cultural do ser humano, resultado da relação deste com o meio em que vive. Nesse trabalho testamos a hipótese de que os/as agricultores/as agroecológicos teriam maior conhecimento e integração da biodiversidade de insetos em seus cultivos; por outro lado, os trabalhadores rurais, inseridos na agricultura convencional, trariam uma percepção mais excludente da biodiversidade de insetos, com ênfase em seus aspectos negativos.

22 As falas de nossos/as colaboradores/as estão em itálico a fim de diferenciar das citações de demais autores/as com quem dialogamos ao longo do capítulo. 
De acordo com os resultados obtidos os dois grupos demostraram conhecer os insetos, principalmente os que mais ocorrem em suas áreas de plantio, como relata o trabalhador T2 (2018): “[...] geralmente assim, no plantio aqui, o que a gente mais ver é a formiga de roça, outros tipos de insetos é a mosca branca que aparece geralmente na melancia, é o que mais a gente ver assim". O agricultor A5 (2018) também cita a ocorrência dos insetos, principalmente em períodos chuvosos, quando os insetos se reproduzem. Assim, ele disse que "[...] tem, e aparece muito, principalmente nessa época de chuva, que eles se reproduzem. No quintal eu vejo uma diversidade grande, mais até que no lote".

Os insetos mais conhecidos e que são citados pelos/as agricultores/as agroecológicos são a mosca branca, gafanhoto, grilo, lagartas, formiga, pulgão e a joaninha. Os/as trabalhadores rurais mencionam formigas, cupins, abelhas, gafanhoto e lagarta. Esse conhecimento, segundo a maioria dos trabalhadores rurais, foi adquirido no dia a dia, com o seu trabalho, suas observações e com diálogo com outras pessoas, como citou T2 (2018): "[...] a gente vai aprendendo no dia a dia, vai vendo, outras pessoas vão falando pra gente, aí a gente vai tomando conhecimento". Porém, um dos cinco entrevistados, T1 (2018), descreveu que o conhecimento sobre os insetos foi adquirido, principalmente, em cursos de capacitação voltados para combater os insetos na plantação. Como é possível observar na fala de T1 (2018):

Eu trabalhei durante oito anos numa empresa que na época era a maior produtora de mamão do Rio Grande do Norte, e eu era responsável por essa área aí de pulverização e nutrição, então eu sempre fazia cursos direcionados para essa área, inclusive na UFERSA, curso assim, de mais tempo, de quatro, seis meses. Eu acho que foram quatro lá, foram, algumas palestras que a gente sempre tinha.

Os modos de aprendizagem relatada pelos/as agricultores/as agroecológicos são variados, contudo, em alguns pontos se relacionam com as formas de aprendizagem dos trabalhadores rurais, pois eles mencionam que esse conhecimento foi adquirido em cursos, troca de experiências, no dia a dia e em conversas entre amigos. O conhecimento é elaborado em muitas circunstâncias, sobretudo o conhecimento popular, que sempre está sendo 
produzido e compartilhado no cotidiano das práticas. Gliessman (2000, p. 54) traz a importância de "Valorizar o conhecimento local e empírico dos/as agricultores, a socialização desse conhecimento e sua aplicação ao objetivo comum da sustentabilidade". Gliessman (1990) coloca o conhecimento popular local como um dos critérios para se obter uma agricultura sustentável. Feiden (2005) põe o conhecimento tradicional das populações como princípio da agroecologia. Assim também podemos considerar esse conhecimento como um patrimônio para essas populações, pois como afirma Isac Chiva (1995, p. 110), "os elementos constitutivos, ao mesmo tempo culturais e naturais do patrimônio rural, agrupam a arquitetura, a organização do habitat, a paisagem, no sentido ecológico do termo, as técnicas e os saberes indispensáveis [à vivência comunitária e à comunicação]".

Os trabalhadores rurais e os/as agricultores/as agroecológicos relatam que a principal maneira de identificar e diferenciar os insetos uns dos outros se dá principalmente pelos aspectos visuais, como o tamanho e a coloração. O trabalhador T2 (2018) demostrou isso em sua fala:

[...] visualmente, assim, a gente tem mais conhecimento do gafanhoto, né? Que ele tem várias cores: tem ele verdinho, tem outros pintados, tem de vários jeitos. É, abelhas também tem bastante, tem bastante abelha: tem a abelha italiana que chama, né? Tem aquela pretinha que a gente aqui chama de abelha de arapuá, tem bastante.

Por sua vez, quando questionados sobre a importância dos insetos, os/ as agricultores/as agroecológicos apresentaram percepções diferentes e, apenas um, contrariou a nossa hipótese, uma vez que ele acredita que os insetos só causam danos e destruição. Já os outros quatro têm a opinião de que os insetos causam danos, porém, sabem da importância que os insetos têm para o ambiente como ferramentas para o equilíbrio ecológico. O agricultor agroecológico A2 (2018) esboçou essa compreensão em sua fala:

Certeza, né? É quem faz o equilíbrio, né? Tem os insetos que é prejudicial, mas tem outros insetos que faz bem a propriedade, um equilíbrio que sempre tem. A joaninha, lá tem muita a joaninha, né? Outro que eu chamo o grilo noturno, aquele que é preto, combate outros insetos mais miudinhos que a gente só encontra a noite, que ele se alimenta de inseto, né? 
Essa percepção da importância dos insetos também foi descrita no discurso do agricultor agroecológico A5 (2018):

Eu creio que sim, eu acho que cada qual tem o seu papel na natureza, eu acho que eles têm importância sim, eles mantem o equilíbrio do ecossistema do ambiente em si, eles estão ali se alimentando das plantas é o alimento deles, mas eu acho que eles estão ali também para equilibrar pra dá um equilíbrio, servi de alimento pra outro também.

A importância atribuída aos insetos por dois trabalhadores rurais foi relacionada aos danos e destruições, já três enfatizaram a importância na cadeia alimentar, no qual gera um equilíbrio ao ambiente não prejudicando os seus cultivos, ajudando ainda na produção das frutas com a polinização. O trabalhador T1 (2018) demostrou este ponto de vista:

Com certeza contribuem, é o equilíbrio, quando você tem vários insetos um se alimenta do outro, então quando você faz uma aplicação indevida, que você mata uma população mais do que outra, naturalmente uma população daquela vai evoluir. E no caso de uma evolução de uma cigarrinha, de um ácaro, de um inseto que causa danos a gente vai ter sérios danos, porque vai ficar bem mais difícil controlar, quem lhe ajudava você matou, então desequilibra.

Essa ideia de causadores de problema é um rótulo associado aos insetos, essa impressão apareceu no discurso dos membros dos dois grupos, quando perguntamos se os insetos causavam problemas em suas plantações, todos relataram ter problemas com insetos em seus cultivos, principalmente em períodos de chuva, uma dinâmica natural, pois esse período se configura como uma estação de reprodução, aonde as populações dos diferentes insetos tende a aumentar. O agricultor A2 (2018) citou que "[...] no inverno que acontece isso, como vem a borboleta aí depois vem a lagarta. É, o maior problema é esse, por exemplo, a lagarta, você sabe que quando dá muito é como se fosse uma praga, come tudo, mais é só período de inverno". Já os/as trabalhadores/as rurais, dois dos cinco descrevem que no momento não existem muitos problemas com insetos, e os outros três citam problemas, segundo eles pontuais, principalmente na melancia com a mosca branca e com a lagarta. 
As formas de controlar os insetos presentes na agricultura convencional e na agroecológica é um diferencial entre esses dois modelos. Almeida, Oliveira e Bezerra (2008) descrevem que a agricultura agroecológica busca respeitar os mecanismos da natureza promovendo a sustentabilidade, considerando os agroecossistemas como elementos vivos. Assim os/as agricultores/as realizam um manejo que se dá com base em produtos naturais. As principais práticas utilizadas pelos/as entrevistados/as são a base de produtos naturais, como compostos de nim (Azadirachta indica), urina de vaca, pimenta malagueta, calda nutritiva, todos os produtos naturais que são usados para controlar as populações de insetos. Além disso, um dos/as agricultores/as diz não fazer nem um tipo de controle, visto que, segundo ele, quando a ocorrência de insetos em alguns períodos é de grande proporção e não tem como controlar, assim ele prefere aguardar passar esse período.

O nim é uma planta que é bastante utilizada pelos/as agricultores/as agroecológicos. Martinez (2002) destaca o efeito do nim no controle de alguns insetos, com baixa toxicidade para o homem e para os inimigos naturais. Ainda descreve que além de ser utilizado como inseticida natural, faz-se uso medicinal, veterinário e na indústria de cosmético. Os/as agricultores/as consideram como uma planta que serve para afastar os insetos dos cultivos, como descreveu o agricultor A1 (2018): "[...] o ninho (sic), que a gente bota ele de molho, ai passa três dias, aí ele fica bem cheirosinho, aí a gente pulverizar com o ninho, com a urina de gado também, aí afasta eles".

Já os trabalhadores rurais utilizam o manejo convencional, fazendo uso de produtos químicos. Todos relataram fazer uso de agrotóxico, com citou o trabalhador T2 (2018): "[...] geralmente é com agrotóxico, com veneno. Tem outra também, um tipo de praga que eu não sei dizer, que ela ataca o mamão, ela é combatida só com produtos de limpeza, geralmente é com detergente, coloca na água, aí faz a aplicação na folha". Apesar de utilizar os agrotóxicos, dois dos cinco trabalhadores/as fazem uso de produtos naturais, como referenciou o trabalhador T1 (2018):

A gente usa químico algumas vezes, mas tento usar os mais leves possiveis, eu só pulverizo de acordo com a necessidade, e química eu pulverizo realmente quando tem necessidade. Meu pulverizador de produtos químicos passa de dois meses, dois meses e meio, parado, sem saber o que é produto químico. 
Os principais que é usado na cultura que eu trabalho hoje são a Beauveria (um fungo utilizado no controle de insetos), que é um fungo, ele parasita alguns insetos específicos, ele tem efeito sobre alguns insetos específicos e uso também um produto chamado azamax, ele é derivado do nim. [...].

As práticas de manejo tanto de um grupo quanto do outro são reflexo da perspectiva que cada modelo adota para a sua prática agrícola. Os trabalhadores rurais, por estarem em uma linha de produção agroexportadora, eles trabalham com a prevenção e controle dos possíveis danos que os insetos podem causar, para não atrapalhar a dinâmica de produção da empresa. Já os/as agricultores/as agroecológicos buscam utilizar os recursos que estão à sua disposição, fazendo um manejo mais sustentável para o controle dos insetos.

\section{Percepções e saberes a respeito dos cupins}

Os cupins são insetos eussociais, com ampla distribuição no globo terrestre, que exercem importante função nos ecossistemas contribuindo na ciclagem de nutrientes e aeração do solo (BIGNELL; EGGLETON, 2000). Essas atividades favorecem o estabelecimento e a manutenção de uma vasta diversidade de espécies vegetais e animais (CONSTANTINO, 2005). Por outro lado, em situação de desequilíbrio ecológico por volta de $10 \%$ das espécies de cupins podem ocasionar prejuízos ao ser humano (CONSTANTINO, 2016; KRISHNA et al., 2013), as quais dentro da perspectiva da agricultura convencional e, popularmente, são as mais conhecidas.

A ocorrência de cupins em plantações não foi relatada pelos trabalhadores rurais. Todos os componentes desse grupo de entrevistados frisaram que nunca tiveram problemas com cupins em suas áreas cultivadas. Resposta semelhante foi concedida pela maioria dos/as agricultores/as agroecológicos. Destes apenas A2 (2018) relatou a ocorrência de cupins em campos com a cultura de milho. Ele cita que "[...] quem vive na agricultura sabe disso, se você deixa o milho muito tempo no campo ele vai dá cupim, não tem nem pra (sic) onde correr, e isso tanto faz você plantar num campo grande ou num pequeno. Deixou, você já sabe". 
Esta dificuldade é superada com uma estratégia de manejo que o próprio agricultor/a agroecológico/a desenvolve a partir de um aprendizado decorrente da observação: "[...] a gente vai plantar de novo, aí já sabe que tem aquele manejo que tem que antecipar: secou, vamos ter que tirar, ou tira ou você perde". O agricultor A2 (2018) promoveu uma relação de coexistência entre o milho e os cupins no seu manejo. Ao evitar queimadas e ao manter as palhas secas do milho no ambiente, o/a agricultor/a deixou recursos alimentares para os cupins entendendo que assim eles não atacariam o seu cultivo: "[...] pode deixar lá que eles vão ficando lá, eles comem os deles e deixa o meu”.

Apesar dos serem mais conhecidos pelos prejuízos que podem causar, os cupins são utilizados de diversas maneiras pela população campo, incluindo a alimentação dos seres humanos e dos animais, na medicina, no manejo do solo, entre outros (Sileshi et al, 2009). Nesse sentido os/as agricultores/as agroecológicos destacam a utilização de cupins como alimento para animais, para as aves, e indicam que contribui no tratamento de doenças, como descreve A2 (2018): "[...] tá doente, vamos atrás de cupins nos matos; é o melhor remédio que tem. Ajuda a combater o gôgo do pintinho novinho, sabe?"

Outro ponto forte bastante destacado entre os/as agricultores/as agroecológicos foi a utilização dos cupins na medicina popular, com a confecção de remédios caseiros, intitulado de lambedor de cupim. O/A agricultor/a agroecológico A5 (2018) destacou: "[...] conheço, conheço alguém que faz, mãe sabe fazer lambedor de cupim. A gente usa muito assim: pra (sic) expectorar o pulmão, pra gripe, pra essas coisas assim, pra cansaço". Entre as indicações descritas pelos/as agricultores/as estão a gripe, o cansaço, a asma. Entre os trabalhadores rurais, apenas o trabalhador T2 (2018) destacou a utilização dos cupins no preparo de remédio caseiro. Ele descreve que "[...] os avós da gente, pais, eles utilizam o cupim de barro pra (sic) fazer lambedor. Muita gente utiliza o cupim pra (sic) fazer lambedor para a gripe, eles falam que é bom".

Esse conhecimento herdado das pessoas mais idosas pode ser entendido como conhecimento tradicional, e patrimônio rural (natural e cultural). Como afirma Flores (1998, p. 11):

A «herança» é hoje mais "pesada», na medida em que do conceito inicial, que se reduzia aos bens culturais de valor material efectivo, passámos para as heranças que identificam e caracterizam um povo, 
uma civilização ou até a humanidade. As tradições populares, os rituais, as crenças e todo um conjunto de actos sociais encontram-se também incluídos neste conceito.

A essa concepção definida por Flores (1998) é necessário acrescentar o patrimônio natural, onde se inscrevem as paisagens e os sítios de reconhecido valor ecológico, estético e memorial.

O conhecimento que os/as agricultores/as possuem acerca dos cupins em alguns casos é desvalorizado por eles mesmos, em sua fala eles minimizaram o próprio saber. Os/as agricultores/as agroecológicos utilizam em suas práticas agroecológicas os cupins, a partir de suas observações e experiências. A4 (2018) destacou utilização do cupinzeiro como composto orgânico, e isso porque os cupinzeiros possuem elevados níveis de nutrientes em suas estruturas que ajudam no desenvolvimento das plantas. Gutierrez e Inocêncio (2009) destacam a utilização de cupinzeiros em cultivos de hortaliças, mostrando uma alternativa viável na utilização de hortas como fertilizantes, se mostrando uma boa aplicação.

Assim, a partir da nossa pesquisa foi possível observar o conhecimento a partir das experiências e das heranças culturais dos/as nossos/as colaboradores/as acerca dos insetos, incluindo os cupins; cada grupo demonstrou conhecer a biodiversidade local, e seus valores para o ambiente, como também realizam mecanismo de controle que estão de acordo com as suas respectivas perspectivas agrícolas. Todo esse conhecimento precisa ser reconhecido como patrimônio rural ambiental e cultural. Afinal, “Todos estes elementos são um patrimônio vivo. Os diferentes actores do mundo rural, interligando-se com eles, conferem-lhe um sentido e um valor para a colectividade e para o território" (Guia Observação do Patrimônio Rural, 2009, p. 19). 


\section{REFERÊNCIAS}

ALMEIDA, M. V. R.; OLIVEIRA, T. S.; BEZERRA, A. M. E. Biodiversidade em sistemas agroecológicos no município de Choró, $\mathrm{CE}$, Brasil. Ciência Rural, p. 1-8, 15 nov. 2008. Disponível em: http://www.scielo.br/pdf/ cr/2009nahead/a153cr319.pdf. Acesso em: 13 abr. 2020.

BIGNELL, D. E.; EGGLETON, P. Termites in ecosystems. In: ABE, T.; BIGNELL, D. E.; HIGASHI, M. (Ed.). Termites: evolution, sociality, symbioses, ecology. Springer, Dordrecht, 2000. Disponível em: https:// doi.org/10.1007/978-94-017-3223-9_17. Acesso em: 10 set. 2020.

CHIVA, I. Patrimoines culturel, naturel et aménagement du territoire rural. In: ÉCOLE NATIONAL DU PATRIMOINE, PATRIMOINE CULTUREL, PATRIMOINE NATUREL. Paris: La Documentation Française, 1995. p. 108-117.

CONSTANTINO, R. Padrões de diversidade e endemismo de térmitas no bioma cerrado. In: SCARIOT, A. O.; SILVA, J. C. S.; FELFILI, J. M. (Ed.). Biodiversidade, ecologia e conservação do cerrado. Brasília: Ministério do Meio Ambiente, 2005. p. 319-333.

CONSTANTINO, R. On-Line termites database. Brasília: UNB, 2016. Disponível em: https://cutt.ly/NfTMQzN. Acesso em: 13 abr. 2020. CUNHA, D. A. S.; NÓBREGA, M. A. S.; ANTONIALLI JUNIOR, W. F. Insetos polinizadores em sistemas agrícolas. Ensaios e Ciências, v. 4, n. 18, p. 22-25, abr. 2015. Disponível em: https://cutt.ly/mfTMPyJ. Acesso em: 25 abr. 2020. 
DIRZO, R.; YOUNG, H. S.; GALETTI, M.; CEBALLOS, G.; ISAAC, N. J. B.; COLLEN, B. Defaunation in the Anthropocene. Science, v. 345, n. 6195, p. 401-406, 24 jul. 2014.

EGGLETON, P. et al. The diversity, abundance and biomass of termites under differing levels of disturbance in the Mbalmayo Forest Reserve, southern Cameroon. Philosophical Transactions of the Royal Society of London, v. 351, p. 51-68, 1996.

FEIDEN, A. Agroecologia: introdução e conceitos. In: AQUINO, A. M.; ASSIS, R. L. (Ed.). Agroecologia: princípios e técnicas para uma agricultura orgânica sustentável. Brasília: Embrapa Informação Tecnológica; Seropédica: Embrapa Agrobiologia, 2005.

FLORES, J. M. Patrimônio: do monumento ao território urbano. In: URBANIDADE e patrimônio. Lisboa: IGAPHE; URBE, 1998. p. 11-17. GAIOVICZ, E. F.; SAQUET, M. A. Modernização da agricultura e agroecologia. [S.l.:s.n.], 2009.

GIL, A. C. Métodos e técnicas de pesquisa social. 7. ed. São Paulo: Atlas, 2019.

GLIESSMAN, S. R. (Ed.). Agroecology: researching the ecological basis for sustainable agriculture. New York: Springer-Verlag, 1990.

GLIESSMAN, S. R. Agroecologia: processos ecológicos em agricultura sustentável. 4. ed. Porto Alegre: UFRGS, 2008.

GLIESSMAN, S. R. Agroecologia: processos ecológicos em agricultura sustentável. Porto Alegre: UFRGS, 2000.

CONCEITO de Patrimônio Rural. In: GUIA observação do patrimônio rural. Lisboa: DSATAR; EPDTR, 2009. Disponível em: https://cutt.ly/ bfT1ppw. Acesso em: 25 abr. 2020.

GUTIERREZ, R. S.; INOCÊNCIO, M. F. Utilização de ninhos de cupins no cultivo de hortaliças. Revista Brasileira de Agroecologia, v. 4, n. 2, p. 935-938, nov. 2009. Disponível em: https://bit.ly/3bOyos7. Acesso em: 07 mar. 2018. 
KRISHNA, K.; GRIMALDI, D. A.; KRISHNA, V.; ENGEL, M. S. Treatise on the Isoptera of the world: 1. Introduction. Bulletin of the American Museum of Natural History, v. 377, n. 1, p. 1-200, 2013.

MACENA, V. M. Abelhas visitantes florais, potenciais polinizadores do algodoeiro (Gossypium hirsutum L.) em cultivo agroecológico. Dissertação (Mestrado) - Universidade Federal do Ceará, Fortaleza, 2011.

MARCONI, M. A.; LAKATOS, E. M. Fundamentos de metodologia científica. 7. ed. São Paulo: Atlas, 2010.

MARIANI, C. M.; HENKES, J. A. Agricultura orgânica x agricultura convencional soluções para minimizar o uso de insumos industrializados. Revista Gestão \& Sustentabilidade Ambiental, v. 2, n. 3, p. 315-338, 1 mar. 2015. Disponível em: https://bit.ly/2FsBDt5. Acesso: 07 mar. 2018.

MARTINEZ, S. S. (Ed.). O nim Azadirachta indica: natureza, usos múltiplos, produção. Londrina: Instituto Agronômico do Paraná, 2002.

PARRA, J. R. P.; BOTELHO, P. S. M.; CORRÊA-FERREIRA, B. S.; BENTO, J. M. S. Controle biológico no Brasil: parasitóides e predadores. São Paulo: Manole, 2002.

PENHA, R. R. P. Agricultura e biodiversidade de insetos: o conhecimento dos/as agricultores/as e produtores/as rurais do oeste potiguar sobre cupins. 2018. 100 f. Trabalho de Conclusão de Curso (Licenciatura Interdisciplinar em Educação do Campo) Universidade Federal Rural do Semi-Árido, Mossoró, 2018.

SANTOS, R. C.; OLIVEIRA, G. B. Um estudo sobre o cultivo de frutas como alternativa de desenvolvimento do sub-médio São Francisco.

Revista das Faculdades Santa Cruz, Curitiba, v. 7, n. 2, p. 31-47, jul. 2009. Disponível em: https://bit.ly/35zgeJR. Acesso em: 07 mar. 2018.

SILESHI, G. W.; NYEKO, P.; NKUNIKA, P. O. Y.; SEKEMATTE, B. M.; AKINNIFESI, F. K.; AJAYI, O. C. Integrating ethno-ecological and scientific knowledge of termites for sustainable termite management 
and human welfare in Africa. Ecology and Society, v. 14, n. 1, 2009. Disponível: https://www.ecologyandsociety.org/vol14/iss1/art48. Acesso em: 12 set. 2018.

STEFFEN, G. P. K.; STEFFEN, R. B.; ANTONIOLLI, Z. I. Contaminação do solo e da água pelo uso de agrotóxicos. Tecnológica, v. 1, n. 15, p. 15-23, jun. 2011. Disponível em: https://online.unisc.br/seer/index. php/tecnologica/article/view/2016. Acesso em: 25 mar. 2018.

TAVARES, E. D. Da agricultura moderna à agroecologia: análise da sustentabilidade de sistemas agrícolas familiares. Fortaleza: Banco do Nordeste do Brasil; Embrapa, 2009.

TILMAN, D. The Ecological consequences of changes in biodiversity: a search for general principles101. Ecology, [s.l.], v. 80, n. 5, p. 14551474, jul. 1999. 